\title{
SOCIAL MEDIA EXPOSURE AND MENTAL HEALTH DURING COVID-I 9 OUTBREAK
}

\section{Ayesha Sarwar', Sumbul Liaqat', Hafiz Muhammad Umar Masood', Nazish Imran ${ }^{3 \otimes}$}

\section{ABSTRACT}

OBJECTIVE: To investigate relationship of social media exposure with prevalence of depression and anxiety among general public in Lahore, Pakistan during the COVID-19 outbreak.

METHODS: A web-based cross-sectional study was conducted via Google forms in June-July 2020 among Pakistani citizens aged $\geq 18$ years. Purposive convenient sampling was done. The questionnaire constituted sociodemographic data, information regarding social media exposure, and scales to assess depression and anxiety. Social media exposure was measured by a questionnaire based on previous literature while depression and anxiety were measured by WHO-Five Well-Being Index (WHO-5) and Generalized Anxiety Disorder (GAD-7) scale respectively. Differences in depression and anxiety between groups and their associations with their social media use were examined through Chi-square test.

RESULTS: Out of 516 participants who completed the questionnaire, 447 $(86.6 \%)$ had frequent exposure to social media. Facebook $(n=345 ; 66.9 \%)$ and WhatsApp ( $n=224 ; 43.4 \%)$ were the most used platforms to obtain COVID- 19 related news. The prevalence of depression, anxiety, and combined depression and anxiety in the sample was $46.3 \%(n=239), 45.5 \%(n=235)$, and $29.7 \%$ $(n=153)$ respectively. Statistically significant association was observed between depression and social media exposure $(p<0.00 \mathrm{I})$ and the combination of depression and anxiety and social media exposure $(p<0.05)$, but not with anxiety. About $56.0 \%(n=289)$ participants believed that publishing more COVID- 19 related news leads to fear and panic.

CONCLUSION: People with frequent social media exposure during COVID19 experienced detrimental effects on mental health. The awareness about limiting social media exposure during the pandemic and psychological support is required to safeguard their well-being.

KEY WORDS: COVID-19 (MeSH); Mental Health (MeSH); Social Media (MeSH); Depression (MeSH); Anxiety (MeSH), Pakistan (MeSH).

THIS ARTICLE MAY BE CITED AS: Sarwar A, Liaqat S, Masood HMU, Imran N. Social media exposure and mental health during COVID-19 outbreak. Khyber Med Univ J 202I;13(2):9l-6. https://doi.org/ 10.35845/kmuj.2021.20668.

\section{INTRODUCTION}

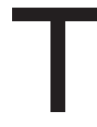
he current spread of COVID-19 in Pakistan took its toll on both the physical and mental health of the population.' With the increasing number of cases, the government implemented a smart lockdown for the safety of the public. This confinement, on one hand, helped in controlling the spread of disease and on the other hand, caused people to spend more time on various social media platforms e.g. Facebook, Instagram, WhatsApp,
YouTube, Twitter, etc.' Undoubtedly, these platforms not only proved to be an important tool of socialization as suggested by literature but also kept home business and home education alive via video calls and zoom conferences. ${ }^{2}$ However, a study done in Italy provided data on the time spent on social media during the lockdown and suggested that people tend to spend more time on social media before going to bed and this habit has led to changes in their sleep patterns, stress, and anxiety. ${ }^{3}$ Furthermore, although social media was the main
I: House Officer, Mayo Hospital, Lahore, Pakistan.

2: Medical Student (Final Year MBBS), Fatima Memorial College of Medicine and Dentistry, Lahore, Pakistan.

3: Department of Child \& Family Psychiatry, King Edward Medical University/Mayo Hospital, Lahore, Pakistan.

Email凶: nazishimrandr@gmail.com

Date Submitted: August 13,2020

Date Revised: April 2I, 202I

Date Accepted: May 0I, 2021

source of accessing information during the COVID-I 9 pandemic, it also became a major source of false information and rumors related to the etiology, effects, and treatment of the disease. This infodemic has been linked with causing a state of panic in people that also led to the adverse psychological impact. ${ }^{4.5}$ In a study conducted on a university lockdown after a shooter incident in the United States, it was established that people receiving conflicting information via text messages and social media reported much higher levels of acute stress. ${ }^{6}$

Hence psychological effects of social media exposure are not only limited to its excessive use but also to the authenticity of the information provided. While the illness itself is one of the major causes of anxiety, depression, and fear of death, this psychological impact due to social media (mis)information overload can also have a lasting effect on the overall wellbeing of the population. ${ }^{5}$ It is, therefore, necessary to establish a relationship between social media exposure and hype created by misinformation overload with the well-being of the population. Previous studies have shown a relationship between exposure to mass trauma via media and increased symptoms of posttraumatic stress disorder. ${ }^{7}$ Similarly, a study on the HINI pandemic in 2009 reported a sense of fear and worry among participants who had information overload via various media sources. ${ }^{8}$

Therefore, the significance of the relationship between social media exposure and the prevalence of depression and anxiety cannot be overlooked. Limited literature 
SOCIAL MEDIA EXPOSURE AND MENTAL HEALTH DURING COVID-19 OUTBREAK

TABLE I: PARTICIPANTS' CHARACTERISTICS AND FREQUENCY OF SOCIAL MEDIA EXPOSURE

\begin{tabular}{|c|c|c|c|c|c|c|}
\hline \multirow{2}{*}{\multicolumn{2}{|c|}{ Demographics }} & \multicolumn{4}{|c|}{ Social Media Exposure } & \multirow[b]{2}{*}{ p-value } \\
\hline & & $\begin{array}{c}\text { Total } \\
\text { N (\%) }\end{array}$ & $\begin{array}{c}\text { Less } \\
\text { N (\%) }\end{array}$ & $\begin{array}{c}\text { Sometimes } \\
\mathbf{N}(\%)\end{array}$ & $\begin{array}{c}\text { Frequently } \\
\text { N (\%) }\end{array}$ & \\
\hline \multicolumn{2}{|l|}{ Overall } & $516(100)$ & $22(4.2)$ & $47(9.1)$ & $447(86.6)$ & \\
\hline \multirow{2}{*}{ Gender } & Male & $203(39.3)$ & $13(2.5)$ & $27(5.2)$ & $163(31.6)$ & \multirow{2}{*}{$0.003 *$} \\
\hline & Female & $313(60.7)$ & $9(1.7)$ & $20(3.9)$ & $284(55.0)$ & \\
\hline \multirow{4}{*}{ Marital Status } & Single & $427(82.8)$ & $16(3.1)$ & $37(7.2)$ & $374(72.5)$ & \multirow{4}{*}{$0.001 *$} \\
\hline & Married & $77(14.9)$ & $4(0.8)$ & $10(1.9)$ & $63(12.2)$ & \\
\hline & Separated/Divorced & $4(0.8)$ & $2(0.4)$ & $0(0.0)$ & $2(0.4)$ & \\
\hline & Prefer not to say & $8(1.6)$ & $0(0.0)$ & $0(0.0)$ & $8(1.6)$ & \\
\hline \multirow{2}{*}{ Area } & Urban & $47 \mid(9 \mid .3)$ & $17(3.3)$ & $42(8.1)$ & $412(79.8)$ & \multirow{2}{*}{$0.048 *$} \\
\hline & Rural & $45(18.7)$ & $5(1.0)$ & $5(I .0)$ & $35(6.8)$ & \\
\hline \multirow{5}{*}{ Education } & Illiterate & $\mathrm{I}(0.2)$ & $\mathrm{I}(0.2)$ & $0(0.0)$ & $0(0.0)$ & \multirow{5}{*}{$0.000 * *$} \\
\hline & Up to Grade 5 & $2(0.4)$ & $0(0.0)$ & $0(0.0)$ & $2(0.4)$ & \\
\hline & Up to Matric & $12(2.3)$ & $0(0.0)$ & $\mathrm{I}(0.2)$ & $\mathrm{II}(2 . \mathrm{I})$ & \\
\hline & Graduation & $2 \mid 4(4 I .5)$ & $15(2.9)$ & $18(3.5)$ & $181(35.1)$ & \\
\hline & Professional degree & $287(55.6)$ & $6(1.2)$ & $28(5.4)$ & $253(49.0)$ & \\
\hline \multirow{6}{*}{ Occupation } & Student & $276(53.5)$ & $I I(2 . I)$ & $26(5.0)$ & $239(46.3)$ & \multirow{6}{*}{$0.004 *$} \\
\hline & Housewife & $17(5.3)$ & $\mathrm{I}(0.2)$ & $4(0.8)$ & $12(2.3)$ & \\
\hline & Unemployed & $36(7.0)$ & $3(0.6)$ & $4(0.8)$ & $29(5.6)$ & \\
\hline & Unskilled worker & $10(1.9)$ & $\mathrm{I}(0.2)$ & $0(0.0)$ & $9(1.7)$ & \\
\hline & Skilled workers & $74(14.3)$ & $6(1.2)$ & $\mathrm{II}(2 . \mathrm{I})$ & $57(11.0)$ & \\
\hline & Healthcare workers & $103(20.0)$ & $0(0.0)$ & $2(0.4)$ & $101(19.6)$ & \\
\hline
\end{tabular}

*P value $<0.5$; **P value $<.001$

is available regarding the prevalence of psychological disorders among people who are excessively exposed to social media during this pandemic. We were unable to find any published literature on this topic from Pakistan and to address this knowledge gap, the current study aims to describe the prevalence and association of two major psychological disorders-anxiety and depression among the general public in Lahore, and manifest their relationship with social media exposure during COVID-19 outbreak.

\section{METHODS}

The study was conducted during June July 2020. Ethical approval was obtained from the Institutional Review Board of King Edward Medical University, Lahore, Pakistan (Ref 46I/RC/KEMU). The study was conducted in conformity with the "Ethical principles for medical research involving human subjects" of the Helsinki Declaration. The sample size of 384 subjects was estimated by using a 95\% confidence level, $5 \%$ absolute precision with an expected percentage of depression and anxiety during COVID19 as $48.3 \%$.' It was a web-based crosssectional study conducted via Google form to avoid face-to-face visits and physical contact for collecting data. The link was sent to various WhatsApp groups. Informed written consent was taken from all the participants before filling the questionnaire. The survey was anonymous, and confidentiality was assured. The questionnaire was based on previous literature on the topic and included demographic information form, information about social media exposure, and scales to assess psychological morbidity.' Demographic information form collected data like age, gender, marital status, education, occupation, area, etc. To assess social media exposure, participants were asked questions regarding the frequency of social media use since Corona outbreak (options were never, once in a while, sometimes, often, \& very often), social media platform details (such as Facebook, WhatsApp, Instagram, etc.) for COVID-19 related news, duration of exposure (less than I hour, I-2 hours and more than 2 hours) and opinion on effects and personal experience with COVID-19 (yes or no).' The mental well-being of the study sample was assessed by measuring the prevalence of two major psychological disorders; depression and anxiety. Depression was assessed by the WHOFive Well-Being Index (WHO-5). Participants were asked to report the presence of positive feelings in the last 2 weeks on a 6-point scale ranging from all of the time ( 5 points) to at no time $(0$ points), a total score below 13 indicated depression. Anxiety was assessed by the 7-item Generalized Anxiety Disorder (GAD-7) scale which consisted of seven symptoms. ${ }^{10}$ Participants were asked how often each symptom troubled them during the last two weeks. Options included in response were "not at all," "several days," "more than half the days," and "nearly every day," scored as 0, I, 2, and 3 , respectively. A score of 7 or greater was a cut point for identifying cases of anxiety. Data was entered into SPSS-26. Quantitative variables like age were presented as mean $\pm S D$. Qualitative variables like gender were presented as frequency and percentages. Options related to social media exposure were merged into 3 categories i.e., "less", "sometimes" and "frequent". Data for each level for symptoms of depression and anxiety were presented as numbers and percentages. Chi-square test was used to examine differences in anxiety and depression as per their social media use. P-Value $<0.05$ was considered statistically significant.

\section{RESULTS}

Five hundred \& sixteen participants completed the questionnaires. The mean age was $24.5 \pm 5.6$ years. The majority 
SOCIAL MEDIA EXPOSURE AND MENTAL HEALTH DURING COVID-19 OUTBREAK

TABLE II: PREVALENCE OF DEPRESSION, ANXIETY, AND THE COMBINATION OF DEPRESSION \& ANXIETY WITH SOCIAL MEDIA EXPOSURE $(n=5 \mid 6)$

\begin{tabular}{|c|c|c|c|c|c|c|}
\hline \multirow{2}{*}{\multicolumn{2}{|c|}{ Parameters }} & \multicolumn{5}{|c|}{ Social Media Exposure } \\
\hline & & \multirow{2}{*}{$\begin{array}{c}\text { Total } \\
\mathbf{N}(\%) \\
239(46.3)\end{array}$} & \multirow{2}{*}{$\begin{array}{c}\text { Less } \\
\mathbf{N}(\%) \\
7(1.4) \\
\end{array}$} & \multirow{2}{*}{$\begin{array}{c}\text { Sometimes } \\
\mathbf{N}(\%) \\
10(1.9) \\
\end{array}$} & \multirow{2}{*}{$\begin{array}{c}\text { Frequently } \\
\text { N (\%) } \\
222(43.0) \\
\end{array}$} & \multirow{3}{*}{$\begin{array}{c}\text { p-Value } \\
0.000^{*}\end{array}$} \\
\hline Depression (WHO-5\# score & Present & & & & & \\
\hline$<13)$ & Absent & $277(53.7)$ & $15(2.9)$ & $37(7.2)$ & $225(43.6)$ & \\
\hline \multirow{2}{*}{ Anxiety (GAD-7"\# score $>7)$} & Present & $235(45.5)$ & $10(1.9)$ & $17(3.3)$ & $208(40.3)$ & \multirow{2}{*}{0.398} \\
\hline & Absent & $28 I(54.5)$ & $12(2.3)$ & $30(5.8)$ & $239(46.3)$ & \\
\hline \multirow{2}{*}{$\begin{array}{l}\text { Combination of Depression \& } \\
\text { Anxiety }\end{array}$} & Present & $153(29.7)$ & $7(\mathrm{I} .4)$ & $4(0.8)$ & $142(27.5)$ & \multirow{2}{*}{$0.004^{* *}$} \\
\hline & Absent & $363(70.3)$ & $15(2.9)$ & $43(8.3)$ & $305(59.1)$ & \\
\hline
\end{tabular}

of the participants $(91.3 \% ; n=47 I)$ belonged to urban areas, $427(82.8 \%)$ were single, 313 (60.7\%) were females and 276 (53.5\%) were students. Table I gives further demographic details of the sample and their association with social media use. Social media exposure was frequent among all demographic variables. Chi-square revealed a statistically significant association of social media exposure across all demographics (Pvalue $<0.05)$.

About $86.6 \%(n=447)$ of participants were frequently exposed to social media during the week before the study. Frequent social media exposure was higher in females $(n=284 / 3 \mid 3 ; 90.7 \%)$ than males $(n=163 / 203 ; 80.3 \%)$. Facebook $(n=345,66.9 \%)$, WhatsApp $(n=224,43.4 \%)$, Instagram $(n=145$, $28.1 \%)$, Twitter $(n=|4|, 27.3 \%)$ and YouTube $(n=134,26.0 \%)$ were the most commonly used platforms to get news or information about COVID-19 included. The least used platforms were Snapchat $(n=19,3.7 \%)$, Linkedln $(n=16,3.1 \%)$, TikTok $(n=15,2.9 \%)$ and COVID-19 website $(n=7,1.4 \%)$. About $91.5 \%$ of participants $(n=472)$ reported the use of social media for less than two hours on COVID-19 related news. More than half of the participants $(n=289,56.0 \%)$ believed that publishing more news related to COVID-19 on social media has spread fear and panic among people, while I 34 (26.0\%) were unsure about it. One hundred and fourteen participants (22.1\%) either tested positive themselves or had any family member who tested positive.

The prevalence of depression (WHO-5 score $<13$ ) in the sample was $46.3 \%$ $(n=239)$. The prevalence of depression was higher among females ( $53.6 \%$ ) than among males (35.0\%). There was a statistically significant difference in social media exposure among depressed and non-depressed groups ( $\mathrm{p}$-value $<0.00 \mathrm{I}$ ). Chi-square analysis also showed a statistically significant association between depression and social media exposure $(\mathrm{p}<0.00 \mathrm{I})$.

The prevalence of anxiety (GAD-7 score $>7)$ was $45.5 \%(n=235)$. The prevalence of anxiety was higher among males (48.3\%) than among females (43.8\%). No statistically significant relationship was established between anxiety and social media exposure in our sample ( $p>0.05)$. [Table II].

Around $56.6 \%(n=292)$ of participants reported that the symptoms of depression and anxiety have made their lives somewhat difficult while $20.9 \%$ $(n=108)$ of participants described them as very or extremely difficult.

The combined prevalence of depression and anxiety in our sample was $29.7 \%$ $(n=153)$. A strikingly significant association between the combination of depression and anxiety and social media exposure was seen $(p<0.05)$. Chi-square analysis also showed a statistically significant association between the combination of depression and anxiety with social media exposure $(\mathrm{p}<0.05)$.

Prevalence of depression, anxiety, and combination of depression \& anxiety in different categories of social media exposure is given in Figure $\mathrm{I}$.

\section{DISCUSSION}

The current study aimed to assess the impact of social media exposure on the psychological well-being in COVID-19 pandemic. We found a significant association of social media use with depression but not with anxiety in our sample during the COVID- 19 pandemic.

Social media exposure is a doubleedged sword. Social media is used as a source of news and acquiring limitless information across the globe, a major means of communication for people as well as maintaining or increasing their social capital. ${ }^{2,11}$ Simultaneously, social media use has been linked with perceived social isolation, depression, and anxiety in all ages. ${ }^{12,13}$ The role of social media exposure becomes tremendously important particularly in a global health emergency like COVID-19 pandemic. With the state implied rules and regulations of social distancing, school closures, as well as a shift to online education and work activities, people are using social networking sites for social support, educational and vocational activities, entertainment purposes, and as a source of information and a health inquiry platform. ${ }^{2,14}$ Hence, it is inevitable that social media exposure increases in comparison to that before COVID-19., A study done in China to analyze the impact of social media exposure on psychological well-being revealed frequent use of social media by most of the participants.' This is concurrent with our study where the majority of the participants reported frequent or very frequent use of social media as compared to a mean time duration of I hour of social media exposure reported in the literature before COVID-19.'2 Congruent to the study by Ahmad AR, et al. Facebook was the most used social networking site for obtaining COVID-19 related news. ${ }^{4}$ An interesting finding in our research was WhatsApp being the second most used source of information for COVID-19, which has been reported as a major means of dissemination of misinformation and conspiracy theories in the literature. ${ }^{15}$ A study in COVID-19 


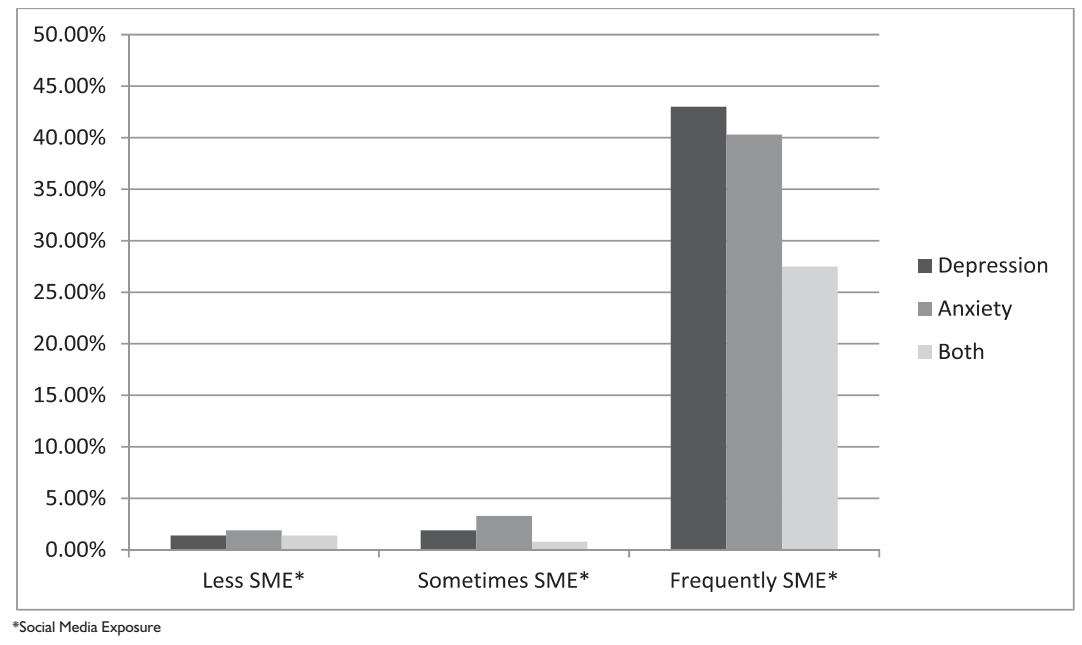

Figure I: Prevalence of depression, anxiety and combination of depression \& anxiety in different categories of Social Media Exposure

pandemic reported participants spending 3 hours on COVID-19 related news respectively. ${ }^{16}$ The majority of participants in our research reported spending less than 2 hours on COVID- 19 related news. The decreased time duration spent on COVID-19 related news can be attributed as one of the reasons for an insignificant association between social media exposure and anxiety.

Pandemics and epidemics have been associated with an increased prevalence of depression and anxiety. Studies related to the Ebola epidemic and the MERS out-break show the increased burden of psychological problems in general populations as well as healthcare workers. ${ }^{17,18}$ Fear of infection and death, social isolation, and quarantine can be the causes of increased prevalence of depression and anxiety during epidemics or pandemics. ${ }^{1,5,19}$ Recent studies report an increased prevalence of moderate to severe depression and anxiety in Pakistani students and healthcare workers during COVID-19. ${ }^{20,21}$ However, none of the studies considered the impact of social media exposure as a contributing factor. Our research demonstrated a strikingly significant association between social media exposure and psychological problems. This can be caused due to multiple associated factors. National lockdown, social distancing, and school and workplace closures have resulted in people staying at home most of the time. This has led to limited availability of entertainment resources, thus the focus turning to the increased use of social media. The general population uses social media to not only acquire news or information but also to post their opinions and findings on different social networking sites as well. ${ }^{4}$ This leads to the cluttering of information available online resulting in an infodemic., ${ }^{5,15}$ Research has shown how misinformation and infodemic impact mental well-being in a pandemic, epidemic, or natural disaster. ${ }^{4,14}$ Similarly, increased exposure to information due to frequent social media use creates fear and panic. ${ }^{4.5}$ This finding became even more significant in those participants of our study who had either tested positive themselves or had a relative/family social media use is inversely related to physical activity which has already been lacking in the current times. Lack of physical activity is negatively correlated with mental well-being. ${ }^{22,23}$ Excessive social media exposure before bedtime has also been shown to cause sleep disturbances due to addicting content and increased exposure to blue light, which also increases the risk for depression and anxiety. ${ }^{3,24}$ Social media exposure is also positively correlated with perceived social isolation, lack of quality time with family members, and less social engage-ment which increases the risk of psychological morbidity. ${ }^{12}$ Gao, et al. argued that the psychological burden is more in females than in males, while Huang stated no major difference in the prevalence for men and member who tested positive. Increased women. ${ }^{1,16}$ Our findings demonstrated an increased prevalence of depression among females and an increased prevalence of anxiety among males. As the expected consequences of this pandemic significantly include anxiety as mentioned in the literature based on previous pandemics, ${ }^{8}$ it is important to acknowledge the higher prevalence of anxiety in our research compared to other studies in COVID- 19., ${ }^{1,21}$ However, in contrast to as hypothesized, its association with social media exposure was not found to be statistically significant in our research. A study conducted in China to assess the correlation of social media exposure and anxiety also reported a statistically insignificant association between the two.'

It is, therefore, of utmost importance to understand the impact of social media exposure on psychological well-being, especially in the COVID- 19 pandemic. It is imperative that social media use is limited to an extent where it can be used for improving social support and communication in times of social isolation and lockdown, but doesn't cause detrimental effects on the mental well-being of the people. ${ }^{2}$ Government interventions to reduce the effect of contributing factors like dissemination of misinformation and conspiracy theories, lack of entertainment and physical activity, and social isolation can help to alleviate fear and panic among people and promote psychological wellbeing. ${ }^{4,25}$ Precedents set from previous pandemics and epidemics can help us devise improved strategies for the use of social media for effective surveillance preparedness. ${ }^{14}$ Social media platforms can collaborate with health governing bodies like WHO or CDC to devise ways to spread awareness about the psychological impact of social media exposure in the COVID-I 9 pandemic. ${ }^{25}$

\section{LIMITATIONS}

This study has several limitations. The survey was done through an online questionnaire to avoid possible infections. Since various social media platforms were used to fill questionnaires, the population with very limited to no social media exposure could not be targeted. Similarly, as the most 
actively available population on social media is usually young adults, the elderly population could not be represented properly. As this study was conducted only during the COVID-19 outbreak, the psychological status and social media exposure in the participants before the outbreak could not be assessed. Furthermore, research has proved that this pandemic has been a source of depression and anxiety in all populations, so an association could be made but a causal relationship between social media exposure and depression and/or anxiety could not be established.

\section{CONCLUSION}

The impact of social media on mental well-being particularly in a pandemic cannot be undermined. Our study determined a high prevalence of psychological burden on the population which positively correlated with social media exposure.

Advanced research pertaining to this topic including cohort studies and case series is requisite to determine the causal factors so that adequate and strategic planning can be done.

\section{REFERENCES}

I. Gao J, Zheng P, Jia Y, Chen H, Mao Y, Chen $S$, et al. Mental health problems and social media exposure during COVID-19 outbreak. PLoS One 2020 । 6;। 5(4):e0231924. https://doi.org/10.137I/journal.pon e.0231924

2. Singh P, Manisha A. Social Media: A tool for Socialization during Lockdown in Delhi and NCR. Int J Transform Media Mass Commun 2020;5(I):I4-20.

3. Cellini N, Canale N, Mioni G, Costa S. Changes in sleep pattern, sense of time and digital media use during COVID-I 9 lockdown in Italy. J Sleep Res 2020:el3074. https://doi.org/ |0. I | | |/jsr. | 3074

4. Ahmad AR, Murad HR. The impact of social media on panic during the COVID-I9 pandemic in Iraqi Kurdistan: online questionnaire study. J Med Internet Res 2020;22(5): el9556. https://doi.org//0.2196/ 19556
5. Jungmann SM, Witthöft M. Health anxiety, cyberchondria, and coping in the current COVID-19 pandemic: Which factors are related to coronavirus anxiety? J Anxiety Disord 2020:102239. https://doi.org/ 10.1016/j.janxdis.2020.102239

6. Purgato M, Gastaldon C, Papola D, van Ommeren M, Barbui C, Tol WA. Psychological therapies for the treatment of mental disorders in low- and middle-income countries affected by humanitarian crises. Cochrane Database Syst Rev 2018:CD0III849. https://doi.org/ I0.1002/I465I858.CD0I I849.pub2

7. Neria Y, Sullivan GM. Understanding the mental health effects of indirect exposure to mass trauma through the media. JAMA 20II;306(I2): I 374-5. https://doi.org/ I0.100 I/jama.20II.I358

8. Davis M, Lohm D, Flowers P, Waller E, Stephenson N. "We became sceptics": fear and media hype in general public narrative on the advent of pandemic influenza. Sociol Inq 20।4;84(4):499-5।8. https://doi.org/IIII/j.I0836101.2007.00367.x

9. World Health Organization (WHO). WHO Collaborating Centre in Mental Health. Chinese version of the WHO-Five Well-Being Index. Accessed on: July I3, 2020. Available from URL: http://www.who-5.org

I0. Spitzer RL, Kroenke K, Williams JB, Lowe B. A brief measure for assessing generalized anxiety disorder: the GAD-7. Arch Intern Med 2006; I 66 (I0): 1092-7.

II. Ellison NB, Steinfield C, Lampe C. The benefits of Facebook "friends:" Social capital and college students' use of online social network sites. J Comput Mediat Commun 2007 I; | 2(4): I |43-68. https://doi.org/ |0.1 | | |/soin. 12058

12. Shensa A, Escobar-Viera CG, Sidani JE, Bowman ND, Marshal MP, Primack BA. Problematic social media use and depressive symptoms among US young adults: A nationallyrepresentative study. Soc Sci Med 2017;182:150-7. https://doi.org/ |0.10|6/j.socscimed.2017.03.06 |
13. Keles B, McCrae N, Grealish A. A systematic review: the influence of social media on depression, anxiety and psychological distress in adolescents. Int J Adolesc Youth. 2020;25(I):79-93. https://doi.org/ |0.1080/02673843.20|9.159085 |

14. Sharma M, Yadav K, Yadav N, Ferdinand KC. Zika virus pandemicanalysis of Facebook as a social media health information platform. Am Int J Infect Control 2017;45(3): 30I-2. https://doi.org//0.1016/ j.ajic.2016.08.022

15. Allington D, Duffy B, Wessely S, Dhavan N, Rubin J. Health-protective behaviour, social media usage and conspiracy belief during the COVID19 public health emergency. Psych Med 2020:I-7. https://doi.org/ I0.1017/S003329172000224X

16. Huang Y, Zhao N. Generalized anxiety disorder, depressive symptoms and sleep quality during COVID-19 outbreak in China: a web-based cross-sectional survey. Psych Res 2020 Apr:II 2954. https://doi.org/10.1016/j.psychres. 2020.1I 2954

17. Ji D, Ji YJ, Duan XZ, Li WG, Sun ZQ, Song $X A$, et al. Prevalence of psychological symptoms among Ebola survivors and healthcare workers during the 2014-20 I 5 Ebola outbreak in Sierra Leone: a crosssectional study. Oncotarget 20|7;8(8):|2784-9|. https://doi.org/ 10.18632/oncotarget. 14498

18. Lee SM, Kang WS, Cho AR, Kim T, Park JK. Psychological impact of the 2015 MERS outbreak on hospital workers and quarantined hemodialysis patients. Comp Psych 2018;87:123-7. https://doi.org/ 10.1016/j.comppsych.20।8.10.003

19. Brooks SK, Webster RK, Smith LE, Woodland L, Wessely S, Greenberg $\mathrm{N}$, et al. The psychological impact of quarantine and how to reduce it: rapid review of the evidence. Lancet 2020;395:9/2-20. https://doi.org/ I0.10|6/SO|40-6736(20)30460-8

20. Aqeel M, Shuja KH, Abbas J, Rehna T, Ziapour A. The Influence of Illness Perception, Anxiety and Depression Disorders on Students Mental Health 
during COVID-19 Outbreak in Pakistan: A Web-Based CrossSectional Survey. Research Square (Preprint). https://doi.org/ |0.21203/rs.3.rs-30|28/v|

21. Salman M, Raza MH, Mustafa ZU, Khan TM, Asif N, Tahir H,et al. The psychological effects of COVID-19 on frontline healthcare workers and how they are coping: a web-based, cross-sectional study from Pakistan. medRxiv preprint. 2020 https://doi.org/I0.1 I0I/2020.06.03 .20119867

22. Liu M, Zhang J, Hu E, Yang H, Cheng C, Yao S. Combined patterns of physical activity and screen-related sedentary behavior among Chinese adolescents and their correlations with depression, anxiety and selfinjurious behaviors. Psych Res Behav Manag 2019;12:1041-50. https:// doi.org/I0.2 I 47/PRBM.S220075

23. Pinto AJ, Dunstan DW, Owen N, Bonfá E, Gualano B. Combating physical inactivity during the COVID19 pandemic. Nat Rev Rheumatol 2020: I-2. https://doi.org/ I0.1038/s4I 584-020-0427-z

24. Levenson JC, Shensa A, Sidani JE, Colditz JB, Primack BA. The association between social media use and sleep disturbance among young adults. Prev Med 2016;85:36-4I. https://doi.org/10.1016/j.ypmed.20 |6.01.001

25. Chen Q, Min C, Zhang W, Wang G, Ma X, Evans R. Unpacking the black box: How to promote citizen engagement through government social media during the COVID-19 crisis. Comput Hum 2020:106380. https://doi.org/10.1016/j.chb.2020. 106380

\section{AUTHOR'S CONTRIBUTION}

Following authors have made substantial contributions to the manuscript as under:

AS: Conception and study design, acquisition, analysis and interpretation of data, drafting the manuscript, critical review, approval of final version to be published.

SL \& NI: Acquisition, analysis and interpretation of data, drafting the manuscript, critical review, approval of final version to be published.

HMUM: Acquisition of data, drafting the manuscript, critical review, approval of final version to be published

Authors agree to be accountable for all aspects of the work in ensuring that questions related to the accuracy or integrity of any part of the work are appropriately investigated and resolved.

CONFLICT OF INTEREST
Authors declared no conflict of interest
GRANT SUPPORT AND FINANCIAL DISCLOSURE
Authors have declared no specific grant for this research from any
funding agency in the public, commercial or not-for-profit sectors

\section{DATA SHARING STATEMENT}

The data that support the findings of this study are available from the corresponding author upon reasonable request.

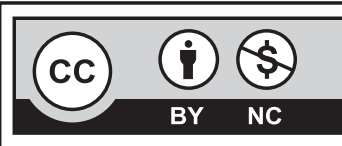

This is an Open Access article distributed under the terms of the Creative Commons Attribution-Non Commercial 2.0 Generic License. 